\title{
Phytoprotection
}

\section{Remerciements - Journée commémorative du centenaire de la SPPQ}

\section{Gilles Émond et Richard Hogue}

Volume 89, numéro 2-3, décembre 2008

Journée commémorative du centenaire de la société de protection des plantes du Québec

Centennial Commemoration of the Québec Society for the Protection

of Plants

URI : https://id.erudit.org/iderudit/038250ar

DOI : https://doi.org/10.7202/038250ar

Aller au sommaire du numéro

Éditeur(s)

Société de protection des plantes du Québec (SPPQ)

ISSN

0031-9511 (imprimé)

1710-1603 (numérique)

Découvrir la revue

Citer ce document

Émond, G. \& Hogue, R. (2008). Remerciements - Journée commémorative du centenaire de la SPPQ. Phytoprotection, 89(2-3), 169-169.

https://doi.org/10.7202/038250ar d'utilisation que vous pouvez consulter en ligne.

https://apropos.erudit.org/fr/usagers/politique-dutilisation/ 


\title{
Remerciements - Journée commémorative du centenaire de la SPPQ
}

\author{
Gilles Émond et Richard Hogue
}

PHYTOPROTECTION 89: 169

Nous tenons à remercier chaleureusement les conférenciers, les partenaires financiers, Mme Hélène Grenier et le personnel du Musée national des beaux-arts du Québec, M. Vincent Lafleur et l'équipe du Restaurant du Musée, les membres du comité organisateur et les nombreux bénévoles sans qui la tenue de la journée commémorative du centenaire n'aurait pu être assurée.

Le comité organisateur était constitué des personnes suivantes:

Direction et coordination:

Conférences:

Affiches:

Bourse étudiante du centenaire:

Comité de la bourse:

Jury:

Prix et Hommages:

Plaque commémorative:

Financement:
Gilles Émond et Richard Hogue

Gérard Gilbert et Gilles Émond

Gilles Émond, Carole Martinez, Valérie Gravel et Richard Hogue

Denis Pageau, Daniel Dostaler, Sylvie Rioux et Anne-Marie Simao-Beaunoir Guy Boivin, Anne Légère et André Lévesque

Daniel Dostaler, Sylvie Rioux, Danielle Bernier et Céline Bélanger

Léon Tartier et Luc Couture

Gérard Gilbert et Richard Hogue

Les personnes suivantes ont également été impliquées dans l'organisation:

Secrétariat et accueil :

Édith Plante, Carolle Fortin, Nathalie Daigle, Claudine Jomphe, Aline Germain, Anne Bédard, Thomas Jeanne, Mario Tésolin

Gestion du site Internet:

Anne-Marie Simao-Beaunoir

Logo:

Ève-Marie Auger-Dostaler

Graphisme:

Julie Nadeau

Prise de photos:

François Charrier

Nous remercions les membres du conseil d'administration de la Société de protection des plantes du Québec pour leur soutien et encouragement ainsi que tous les participants à cette merveilleuse journée commémorative du centenaire de la SPPQ.

Au nom du comité organisateur, merci à tous! 